\title{
Do macroeconomic factors matter for stock returns? Evidence from estimating a multifactor model on the Croatian market
}

\section{Dubravka Benaković}

Ministry of Finance of the Republic of Croatia, Katančićeva 5, 10000 Zagreb, Croatia

dubravka.benakovic@mfin.hr

\section{Petra Posedel}

University of Zagreb, Faculty of Economics \& Business, Trg J. F. Kennedyja 6, 10000 Zagreb, Croatia pposedel@efzg.hr

\begin{abstract}
Factor models observe the sensitivity of an asset return as a function of one or more factors. This paper analyzes returns on fourteen stocks of the Croatian capital market in the period from January 2004 to October 2009 using inflation, industrial production, interest rates, market index and oil prices as factors. Both the direction and strength of the relation between the change in factors and returns are investigated. The analyses included fourteen stocks and their sensitivities to factors were estimated. The results show that the market index has the largest statistical significance for all stocks and a positive relation to returns. Interest rates, oil prices and industrial production also marked a positive relation to returns, while inflation had a negative influence. Furthermore, cross-sectional regression with the estimated sensitivities used as independent variables and returns in each month as dependent variables is performed. This analysis resulted in time series of risk premiums for each factor. The most important factor affecting stock prices proved to be the market index, which had a positive risk premium. A statistically significant factor in 2004 and 2008 was also inflation, marking a negative risk premium in 2004 and a positive one in 2008. The remaining three factors have not shown as significant.
\end{abstract}

Keywords: Factor models, risk premium, stock returns, estimated sensitivities, regression analysis

JEL Classification: C22, E22, G12

\section{Introduction}

Factor or index models observe the sensitivity of an asset return as a function of one or more factors. Depending on the number of factors, there are single-factor or multi-factor models. The basic division of factor models, according to type of factors used, is on the economic and fundamental factor models. Economic factor mod- els use macroeconomic and financial markets variables as factors, while fundamental factor models use firmspecific microeconomic variables, such as financial indicators. The investment risk can be observed through two components: systematic or market risk, which arises from changes in the macroeconomic environment, and unsystematic risk, that is, the unique risk of an individual asset, which may be reduced or even eliminated through diversification. Factor models focus on systematic investment risk, i.e., the one that cannot be avoided by investment diversification.

Factor models are based on the Arbitrage Pricing Theory (APT), introduced by Ross (1976), for more details about APT see for example Campbell, Lo and MacKinlay (1997). Unlike the Capital Asset Pricing Model (CAPM), which estimates the systematic investment risk of an asset by a single factor, the market portfolio, multi-factor models introduce several factors that influence stock returns. However, one of the main limitations of APT arises from the fact that factors, as well as the number of factors, are not known in advance, but they must be determined by statistical or economic analysis.

In accordance with the basic division of factor models of stock returns on economic and fundamental, the literature on factor models can also be regarded in this way. The well-known paper of Fama and French (1992), for example, analyzes firm-specific microeconomic variables such as market beta, firm size, earnings-price ratio, leverage ratio and book-to-market equity in explaining stock returns, thus representing the fundamental factor model. On the other hand, Chen, Roll and Ross (1986) analyze macroeconomic and financial market variables in an economic factor model. Given that this paper investigates macroeconomic factors and stock returns, we present a brief overview of similar studies.

Variables used by Chen, Roll and Ross (1986) in their notable study on U.S. stock returns include industrial production, inflation, risk premium, term structure, market index, consumption and oil prices. The authors found that the industrial production, unanticipated change in the risk premium, unanticipated inflation, and, a slightly weaker, the unanticipated change in term structure, are the most important factors affecting expected stock returns. Unanticipated inflation and change in expected inflation show particularly high significance in the period of highly volatile inflation.

Bodurtha, Cho and Senbet (1989) expanded the work 
of Chen, Roll and Ross (1986) by including international factors. First, they replicated the Chen-Roll-Ross (CRR) analysis by using five CRR domestic factors: anticipated inflation, term premium, U.S. junk bond premium, inflation and the industrial production growth. Only industrial production showed as significant, but a shorter sample period was used than in CRR. Moreover, mentioned domestic factors were enlarged with five international factors: domestic country stock return index, the restof-the-world industrial production growth, the rest-ofthe-world stock return index, the rest-of-the-world bond return index and the oil price. The inclusion of international factors gave better results than the solely domestic case, since more factors, precisely, the rest-of-theworld industrial production growth, domestic industrial production growth and the rest-of-the-world bond returns turned to be significant.

In order to eliminate some economic and econometric difficulties associated with factor analysis techniques, McElroy and Burmeister (1988) modified the APT as a multivariate non-linear regression model. They used four macroeconomic variables, namely, the risk premium, term structure, unexpected deflation and unexpected growth in sales, as well as the residual market factor. Within the multivariate non-linear regression model all five factors showed as significant in explaining stock returns.

Considering that smaller firms have higher average returns, Chan, Chen and Hsieh (1985) investigated the firm size effect on stock returns. The stock returns were analyzed across twenty portfolios according to firm size along with a difference between the smallest size and the largest size portfolios. The set of used macroeconomic variables included market index, monthly growth of industrial production, change in expected inflation, unanticipated inflation, change in the risk premium and the change in the slope of the yield curve. The change in the risk premium showed as the most important factor influencing on the difference in return for firms of different sizes, followed by the market index and the industrial production change.

This paper analyzes returns on fourteen stocks of the Croatian capital market in the period from January 2004 to October 2009. The following macroeconomic and financial market variables are used as factors in the model: inflation, industrial production, interest rates, market index and oil prices. The paper investigates the relation between the change in macroeconomic factors and stock returns, as well as the direction and strength of the relation. In the first part of the paper the model is defined and stocks and factors that will be used in model are chosen. The first step is the multiple regression of stock returns on macroeconomic variables' realizations, which estimates sensitivities of stock returns to factors, measured by beta coefficients. In the next step the estimated beta coefficients are used as independent variables and stock returns in each month as dependent variables in cross-sectional regression. This gives the time series of risk premiums for each macroeconomic factor.

To the best of our knowledge there is no empirical study about factor models of stock returns for the Croatian capital market. Therefore, this study is motivated to be one of the first studies of that kind aiming to open a rather empirically unexplored area about influence of macroeconomic factors on the Croatian capital market. Due to differences between macroeconomic factors influencing the U.S. capital market on the one hand and the Croatian capital market on the other hand, this paper aims to compare a classic implementation of an economic factor model on one representative of transition markets, having as a guide macroeconomic factors influencing stock returns on very developed markets.

\section{Definition of the model}

The econometric model under analysis is given by the following equation: where:

$$
R_{i, t}=a_{i}+\beta_{i, 1} F_{1, t}+\beta_{i, 2} F_{2, t}+\ldots \beta_{i, k} F_{k, t}+{ }_{\varepsilon i, t} \text {, }
$$

$$
\begin{aligned}
\mathrm{R}_{\mathrm{i}}= & \text { return on stock } i \\
\mathrm{a}_{\mathrm{i}}= & \text { constant term } \\
\beta_{\mathrm{i}}= & \text { sensitivity of a stock } i \text { to a set of } n \\
& \text { macroeconomic factors } \\
\mathrm{F}_{\mathrm{n}}= & \text { realizations of macroeconomic factors, } \\
& n=1,2 \ldots, k \\
\varepsilon_{\mathrm{i}}= & \text { disturbance term with an expected value } \\
& \text { of zero }
\end{aligned}
$$

Factor models are based on two main assumptions. The first assumption states that disturbance terms are uncorrelated across stocks, meaning that stock returns change only as a reaction on a specific factor. The second assumption is that disturbance terms are uncorrelated with the factors' values, that is, the result of factor is not related with the disturbance term outcome (Ivanović, 2000).

\subsection{Selection of stocks and factors}

Fourteen stocks that constitute CROBEX index are chosen for the analysis, based on availability and credibility of data. Considering that some stocks that constitute CROBEX index lack sufficiently long time series, while the initial public offers or splits of some stocks distorted their prices, such stocks are not used in the analysis.

Stock prices are observed on a monthly basis, by averaging the daily stock prices in the period from January 2004 to October 2009. The stock return is calculated as the monthly change in the stock price by the following formula: 


$$
R(t)=\log S P(t)-\log S P(t-1),
$$

where $\mathrm{SP}(t)$ is the average stock price in month $t$ and $\mathrm{SP}(t-1)$ is the average stock price in the previous month.

Table 1: Stocks used in the analysis

\begin{tabular}{|r|l|l|}
\hline & Symbol & Company \\
\hline 1 & ADRS-P-A & Adris grupa d.d. \\
\hline 2 & KORF-R-A & Dom Holiding d.d. \\
\hline 3 & PODR-R-A & Podravka d.d. \\
\hline 4 & DLKV-R-A & Dalekovod d.d. \\
\hline 5 & PTKM-R-A & Petrokemija d.d. \\
\hline 6 & ATPL-R-A & Atlantska plovidba d.d. \\
\hline 7 & KOEI-R-A & Končar elektroindustrija d.d. \\
\hline 8 & ERNT-R-A & Ericsson Nikola Tesla d.d. \\
\hline 9 & PBZ-R-A & Privredna banka Zagreb d.d. \\
\hline 10 & JDPL-R-A & Jadroplov d.d. \\
\hline 11 & VDKT-R-A & Viadukt d.d. \\
\hline 12 & THNK-R-A & Tehnika d.d. \\
\hline 13 & TNPL-R-A & Tankerska plovidba d.d. \\
\hline 14 & LEDO-R-A & Ledo d.d. \\
\hline
\end{tabular}

Source: Zagreb Stock Exchange
As already mentioned, the theory of multi-factor models does not define which factors and how many factors should be considered, therefore, this issue remains to be determined by the researcher. Factors in this model are selected based on the literature reviewied in the introduction part of the paper. Regarding the number of factors, recent studies show that it is sufficient to use between three and six factors in the model, see for example Campbell, Lo and MacKinlay (1997). For example, the factors analyzed in Chen, Roll and Ross (1986) for the US capital market are the industrial production, inflation, risk premium, term structure, market index, consumption and oil prices. According to specific macroeconomic influences governing the U.S. capital market, the same macroeconomic variables cannot be applied to the Croatian market due to differences in data availability and, therefore, this paper uses factors adjusted to the Croatian market.

\subsection{Inflation}

Inflation, i.e., a rise in the general level of prices, reduces the real value of money, thereby reducing the expected cash inflow from an asset, exceptions being inflationindexed securities. Investors who own some asset are exposed to changes in inflation, since their payment at the end of period depends on inflation during the holding period. Thus, inflation is expected to affect negatively the stock prices. Along with full employment, maintain-

Table 2: Overview of macroeconomic factors used in the analysis

\begin{tabular}{|c|c|c|}
\hline \multicolumn{3}{|c|}{ Basic series } \\
\hline Symbol & Variable & Source \\
\hline CPI & Consumer Price Index & $\begin{array}{l}\text { First Release Consumer Price Indices, } \\
\text { Central Bureau of Statistics } \\
\text { http://www.dzs.hr }\end{array}$ \\
\hline IP & Industrial Production Volume Index & $\begin{array}{l}\text { First Release Industrial Production Volume Index, } \\
\text { Central Bureau of Statistics http://www.dzs.hr }\end{array}$ \\
\hline ZIBOR & Interest rate on the Croatian interbank market & $\begin{array}{l}\text { Reuters } \\
\text { http://www.reuters.hr }\end{array}$ \\
\hline CROBEX & Zagreb Stock Exchange indeks & $\begin{array}{l}\text { Zagreb Stock Exchange } \\
\text { http://www.zse.hr }\end{array}$ \\
\hline OP & Price of crude oil on world market & $\begin{array}{l}\text { WTRG Economics } \\
\text { http://www.wtrg.com }\end{array}$ \\
\hline \multicolumn{3}{|c|}{ Derived series (Authors' calculations) } \\
\hline Symbol & Variable & Equation \\
\hline$I(t)$ & Annual change in CPI & $\mathrm{I}(t)=\log \mathrm{CPI}(t)-\log \mathrm{CPI}(t-12)$ \\
\hline AIP(T) & Annual change in industiral production volume & $\operatorname{AIP}(t)=\log \operatorname{IP}(t)-\log \operatorname{IP}(t-12)$ \\
\hline $\operatorname{IR}(\mathbf{t})$ & 3-month ZIBOR & $\mathrm{IR}(t)=3$-month ZIBOR in month $t$ \\
\hline MI(t) & Monthly change in CROBEX index & $\mathrm{MI}(t)=\log \mathrm{CROBEX}(t)-\log$ Crobex $(t-1)$ \\
\hline$O(t)$ & Annual change in oil prices & $\mathrm{O}(t)=\log \mathrm{OP}(t)-\log \mathrm{OP}(t-12)$ \\
\hline
\end{tabular}


ing low inflation is the main economic policy task in most countries.

The series for calculation of the inflation rate is the consumer price index (CPI), obtained from the First Release of Central Bureau of Statistics. The annual change in CPI is given by the following formula:

$$
\mathrm{I}(t)=\log \mathrm{CPI}(t)-\log \mathrm{CPI}(t-12)
$$

where $\mathrm{I}(t)$ is the annual change in $\mathrm{CPI}$, that is, the inflation in month $\mathrm{t}, \mathrm{CPI}(t)$ is the $\mathrm{CPI}$ in month $\mathrm{t}$ and $\mathrm{CPI}(t-12)$ is the $\mathrm{CPI}$ in the same month of the previous year.

In Chen, Roll and Ross (1986), the factor of inflation is included through two variables: unanticipated inflation and the change in expected inflation.

\subsection{Industrial production}

Along with gross domestic product (GDP), industrial production is the most widely used measure of economic activity. Given that the GDP data is calculated and published on a quarterly basis and the announcement lags about three months for the reference period, the industrial production is much more appropriate measure of economic activity, since the industrial production data is available on a monthly basis and the announcement is shortly behind the period to which it relates.

The series of industrial production is taken from the First Release Industrial Production Volume Index of Central Bureau of Statistics and by using the following formula the series of annual change in industrial production volume is calculated:

$$
\operatorname{AIP}(t)=\log \operatorname{IP}(t)-\log \operatorname{IP}(t-12),
$$

where $\operatorname{AIP}(t)$ is the annual change in industrial production volume in month $t, I P(t)$ is the Industrial Production Volume Index in month $t$ and $\mathrm{IP}(t-12)$ is the Industrial Production Volume Index in the same month of the previous year.

In Chen, Roll and Ross (1986), industrial production is used as its monthly and annual growth rate.

\subsection{Interest rates}

High interest rates decrease the present value of future cash flows, thus reducing the attractiveness of investment. Therefore, according to economic theory, the increase in interest rates should lead to a drop in stock prices.

The interest rate used in this paper is 3-month ZIBOR (Zagreb Interbank Offered Rates), the reference interest rate on the Croatian interbank market. The official calcu- lation of ZIBOR by maturities is published daily on Reuters system as an arithmetic average of interest rates of eight biggest Croatian banks. The interest rate for each month is calculated as an average of daily interest rates. Therefore we have:

$$
\mathrm{IR}(t)=3 \text {-month ZIBOR in month } t
$$

In Chen, Roll and Ross (1986), interest rates involve two factors: unanticipated change in risk premium and unanticipated change in term structure. The first factor, unanticipated change in risk premium is calculated as the difference between the return on a portfolio of thirteen corporate low-grade bonds (bond credit rating Baa and under) and the return on a portfolio of long-term government bonds. The second factor, unanticipated change in term structure is defined as the difference between the return on a portfolio of long-term government bonds and the return on 1-month treasury bills.

\subsection{The Market index}

It is considered that macroeconomic variables cannot comprise all the information available to the capital market, while stock prices react quickly to publicly disclosed information. Therefore, it is recommended that the factor model includes not only macroeconomic variables, but also financial markets variables.

Market index used in this paper is CROBEX, the official Zagreb Stock Exchange share index, which consists of stocks from 25 companies. The series of index values for each month is calculated by averaging the daily values of CROBEX index, afterwards the monthly change in CROBEX index is calculated by the following formula:

$$
\mathrm{MI}(t)=\log \mathrm{CROBEX}(t)-\log \mathrm{CROBEX}(t-1),
$$

where $\mathrm{MI}(t)$ is the monthly change in market index in month $t, \operatorname{CROBEX}(t)$ is the market index in month $t$ and CROBEX $(t-1)$ is the market index in the previous month.

In Chen, Roll and Ross (1986), two variables are used as market indices: return on equally weighted portfolio of NYSE-listed stocks and the return on a value-weighted portfolio of NYSE-listed stocks.

\subsection{Oil prices}

Number of authors include oil prices in the list of factors that influence stock market returns, see Chen, Roll and Ross (1986). The growth in oil prices increases the uncertainty in the capital market, as well as the risk of inflationary pressures in the economy. Increased oil prices augment the costs of companies, such as transportation and production costs, and eventually, reduce their profits. All of the above will have a negative influence on capital market. 
Prices of crude oil on world market, NYMEX Light Sweet Crude, are used in this paper. The series of the annual change in oil prices was calculated by the following formula:

$$
\mathrm{O}(t)=\log \mathrm{OP}(t)-\log \mathrm{OP}(t-12),
$$

where $\mathrm{O}(t)$ is the annual change in oil prices in month $t, \mathrm{OP}(t)$ is the oil price in month $t$ and $\mathrm{OP}(t-12)$ is the oil price in the same month of the previous year.

\section{Implementation of the model}

After having specified the factors in the previous section, we finally have the equation of the model given by:

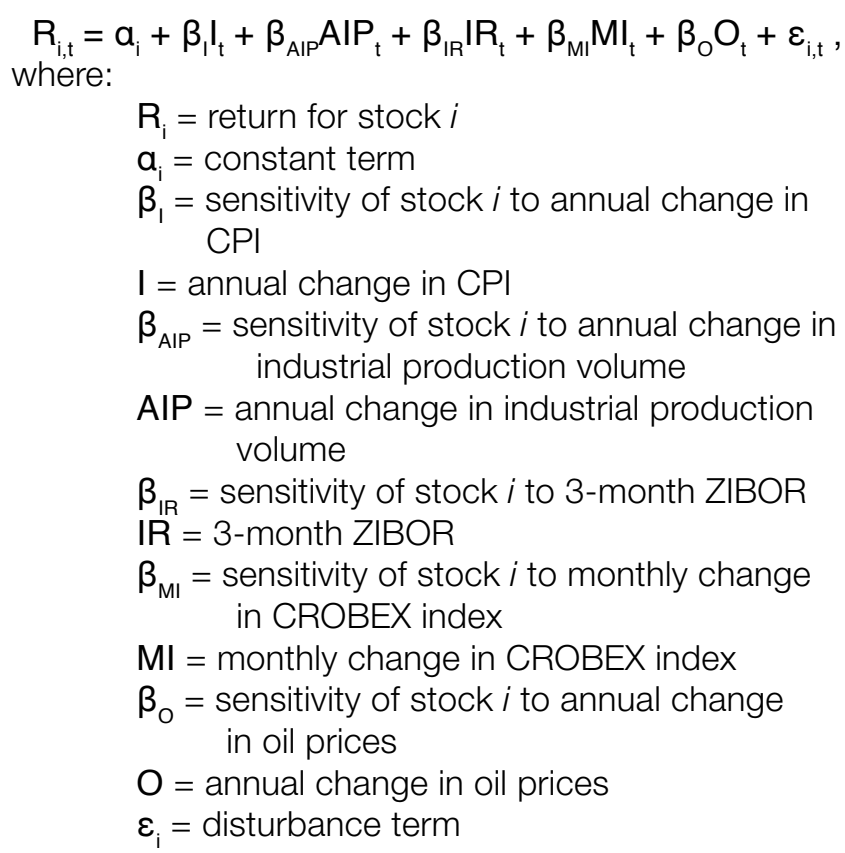

\subsection{Estimation of sensitivities of stock returns to factors}

The first step in the econometric analysis of the model is the multiple regression of stock returns as dependent variable and macroeconomic variables' realizations as independent variables. This gives five regression coefficients for each of fourteen stocks, which estimate the sensitivity of stock returns to changes in each macroeconomic factor, that is, the average change in the stock return (dependent variable) when a particular macroeconomic factor (independent variable) changes by 1 percentage point, holding all the other independent variables constant. Results of the regression analysis are given in Table 3.

As can be seen from the table, the largest statistical significance for all stocks shows the monthly change in the CROBEX index. Given than stocks used in analysis form CROBEX index, such results were expected. Positive signs on regression coefficients of CROBEX index indicate that the growth in CROBEX increases the stock returns. Results show that if CROBEX index rises by 1 percentage point, stock return increases by more than 1 percentage point on average for the majority of stocks.

The interest rate, 3-month ZIBOR, shows statistical significance for totally seven stocks from the sample. Positive regression coefficients signs indicate that the growth in 3-month ZIBOR increases the stock return, which is opposite from the model assumptions.

Inflation, that is, the annual change in CPI, shows significant t-statistics values for six stocks. However, unlike two above mentioned factors, the regression coefficients of stock return to the change in CPI have negative signs, which mean that the inflation growth tends to decrease the stock return. This was expected, since, as already mentioned, inflation reduces the real payoff of investors during the holding period.

The sensitivity of stock returns to changes in oil prices shows the significance for five stocks. Although economic theory says that oil prices should have a negative impact on stock prices, the results indicate a positive sign of regression coefficients. However, regression coefficients have small values (around 0.1), which means that oil prices don't have a significant influence on the dependent variable. In addition, it can be seen that the stocks that show statistical significance and positive sensitivity to changes in oil prices relate to shipping companies, a construction company and a company that produces mineral and liquid fertilizers. A possible explanation would be that it is expected that companies engaged in these activities incorporate increased oil prices into the price of their services and therefore the growth in oil prices won't affect adversely their profits.

The annual growth of industrial production volume, as a measure of economic activity, has a positive effect on the stock return, since economic growth gives a positive signal to capital market. This macroeconomic factor shows statistical significance for three stocks from the sample. The constant term shows statistical significance for only one stock.

\subsection{Estimation of risk premiums for macroeco- nomic factors}

After estimating sensitivities of stock returns to a change in each macroeconomic factor, the next step includes cross-sectional regression in which the estimated sensitivities are used as independent variables and stock returns in each month as dependent variables. This results in time series of risk premiums for each macroeconomic factor for the period from January 2004 to October 2009, which totally makes seventy risk premiums values for each macroeconomic factor. 
Table 3: Sensitivities of stock returns

\begin{tabular}{|c|c|c|c|c|c|c|}
\hline & $\mathbf{I}(\mathbf{t})$ & $\mathbf{A I P ( t )}$ & $\mathbf{I R ( t )}$ & $\mathbf{M I}(\mathbf{t})$ & $\mathbf{O}(\mathbf{t})$ & $\mathbf{a}_{\mathbf{i}}$ \\
\hline ADRS-P-A & 0.194 & 0.147 & 0.646 & 0.996 & -0.020 & -0.059 \\
\hline$t$-stat & 0.433 & 1.049 & 1.433 & $12.070^{*}$ & -0.979 & -1.619 \\
\hline KORF-R-A & -1.552 & 0.171 & 1.325 & 1.199 & 0.032 & -0.053 \\
\hline$t$-stat & $-2.728^{*}$ & 0.963 & $2.321^{*}$ & $11.481^{*}$ & 1.240 & -1.144 \\
\hline PODR-R-A & -0.387 & 0.074 & 0.290 & 0.692 & 0.011 & -0.008 \\
\hline$t-s t a t$ & -0.922 & 0.567 & 0.688 & $8.969^{*}$ & 0.570 & -0.235 \\
\hline DLKV-R-A & -0.279 & 0.010 & 0.620 & 1.330 & 0.042 & -0.033 \\
\hline t-stat & -0.470 & 0.051 & 1.039 & $12.181^{*}$ & 1.533 & -0.678 \\
\hline PTKM-R-A & 0.089 & 0.220 & 2.375 & 1.349 & 0.091 & -0.160 \\
\hline$t$-stat & 0.077 & 0.610 & $2.046^{*}$ & $6.354^{*}$ & $1.707^{*}$ & $-1.709^{*}$ \\
\hline ATPL-R-A & -3.181 & 0.451 & 4.038 & 1.425 & 0.142 & -0.141 \\
\hline$t-s t a t$ & $-2.672^{*}$ & 1.216 & $3.381^{*}$ & $6.521^{*}$ & $2.598^{*}$ & -1.465 \\
\hline KOEI-R-A & -0.270 & 0.429 & 0.832 & 1.408 & -0.024 & -0.037 \\
\hline$t-s t a t$ & -0.426 & $2.174^{*}$ & 1.308 & $12.099^{*}$ & -0.816 & -0.722 \\
\hline ERNT-R-A & -0.909 & 0.508 & 1539 & 0.872 & -0.002 & -0.071 \\
\hline$t-s t a t$ & -1.549 & $2.778^{*}$ & $2.615^{*}$ & $8.094^{*}$ & -0.073 & -1.489 \\
\hline PBZ-R-A & -1.023 & 0.082 & 0.341 & 1.082 & -0.006 & 0.016 \\
\hline$t-s t a t$ & -2.041 & 0.525 & 0.679 & $11.757^{*}$ & -0.262 & 0.402 \\
\hline JDPL-R-A & -3.484 & 0.509 & 3.584 & 1.224 & 0.138 & -0.123 \\
\hline$t-s t a t$ & $-3.185^{*}$ & 1.493 & $3.265^{*}$ & $6.092^{*}$ & $2.733^{*}$ & -1.390 \\
\hline VDKT-R-A & -3.424 & 0.500 & 3.751 & 1.679 & 0.142 & -0.133 \\
\hline$t-s t a t$ & $-2.844^{*}$ & 1.334 & $3.104^{*}$ & $7.596^{*}$ & $2.560^{*}$ & -1.368 \\
\hline THNK-R-A & -0.720 & 0.132 & -0.070 & 1.439 & -0.008 & 0.032 \\
\hline$t-s t a t$ & -1.117 & 0.660 & -0.108 & $12.170^{*}$ & -0.276 & 0.612 \\
\hline TNPL-R-A & -2.792 & 0.213 & 2.291 & 1.066 & 0.086 & -0.053 \\
\hline$t-s t a t$ & $-2.755^{*}$ & 0.675 & $2.253^{*}$ & $5.731^{*}$ & $1.835^{*}$ & -0.649 \\
\hline LEDO-R-A & -0.627 & 0.682 & 1.432 & 1.224 & -0.006 & -0.064 \\
\hline$t-s t a t$ & -0.486 & 1.695 & 1.105 & $5.165^{*}$ & -0.096 & -0.608 \\
\hline
\end{tabular}

Remark: Confidence level is 90\%.

Source: Authors' calculations

Regression results are shown in table 4. Due to large number of values, estimated risk premiums, as well as absolute values of t-statistics, are averaged for several periods. Therefore, as can be seen from table 4 , first the entire period January 2004 - October 2009 is included, which is then divided into several sub-periods, that is, individual years.

Over the entire sample period, from January 2004 to October 2009, only one macroeconomic factor, market, i.e. the CROBEX index, is statistically significant. The risk premium for the market index has a positive sign in the entire period, which leads to a conclusion that investors seek compensation for the risk arising from developments in the capital market.

Observed by individual years, the risk premium for the market index is statistically significant in all years except
2004. CROBEX has a positive risk premium in all years except in 2008, the year characterized by a significant decline in the index and negative developments in the capital market. The negative risk premium could possibly be a result of capital market turbulences, withdrawal of investors and investment in other, primarily safer forms of financial assets. The values of positive risk premium range between $0.01 \%$ and $0.05 \%$, where the highest value was recorded in 2006, but changes in the risk premium are too small to be attributed to some major economic developments in that period. On the other hand, a negative risk premium for CROBEX recorded in 2008 amounted to $0.09 \%$, which is its largest absolute value, and, as already mentioned, is the result of a significant increase in uncertainty on the capital market in that period. 
The risk premium for inflation compensates investors for bearing the inflation risk, that is, the risk that actual inflation may be higher than expected. Risk premium may signal changes in perceived inflation risks or shifts in investors' aversion to inflation risk, see Hördahl (2008). As can be seen from table 4, inflation risk premium shows statistical significance in two years, 2004 and 2008, where the expected inflation show particularly high significance in the period of highly volatile inflation. A similar result was obtained for the Croatian capital market, given that inflation has shown to be a significant factor in 2008, a year characterized by high inflation. The results showed that the market index doesn't have a significant influence on stock returns on the U.S. capital market, neither do

Table 4: Risk premiums for macroeconomic factors

\begin{tabular}{|c|c|c|c|c|c|}
\hline period & $I(t)$ & AIP(t) & IR() & $\mathrm{MI}(\mathrm{t})$ & $O(t)$ \\
\hline I 2004- X 2009 & 0.0001 & 0.0432 & -0.0047 & 0.0072 & 0.2009 \\
\hline t-stat & 1.3288 & 1.2158 & 1.2483 & $3.0460^{*}$ & 1.2351 \\
\hline I - XII 2004 & -0.0299 & -0.0877 & 0.0453 & 0.0204 & -0.4160 \\
\hline t-stat & $1.7239^{*}$ & 0.7252 & 0.8606 & 1.3387 & 1.0535 \\
\hline I - XII 2005 & -0.0004 & 0.1321 & -0.0320 & 0.0189 & 0.6979 \\
\hline t-stat & 1.1176 & 1.6306 & 1.2913 & $1.9510^{*}$ & 1.4990 \\
\hline I - XII 2006 & 0.0053 & 0.0702 & -0.0353 & 0.0516 & 0.3772 \\
\hline t-stat & 1.1428 & 1.2542 & 1.3434 & $2.6178^{*}$ & 0.9926 \\
\hline I - XII 2007 & -0.0033 & 0.1881 & -0.0465 & 0.0257 & 0.9064 \\
\hline t-stat & 0.6295 & 1.3412 & 1.3157 & $2.0764^{\star}$ & 1.4007 \\
\hline I - XII 2008 & 0.0269 & -0.0306 & 0.0279 & -0.0920 & -0.2434 \\
\hline t-stat & $2.4042^{*}$ & 1.0340 & 1.4140 & 5.5481 & 1.2206 \\
\hline I - XII 2009 & 0.0023 & -0.0239 & 0.0158 & 0.0212 & -0.1803 \\
\hline t-stat & 0.8802 & 1.3289 & 1.2681 & $5.0835^{*}$ & 1.2459 \\
\hline
\end{tabular}

Remark: Confidence level is $90 \%$. Source: Authors' calculations

sign on the coefficient was negative in 2004 and positive in 2008. Considering that a year 2004 saw the growth of economic activity, the negative sign on the inflation risk premium could indicate that investors are willing to take risk and hold stocks if they expect that economic expansion will increase the value of their stocks. The positive risk premium for inflation in 2008 indicates that investors required a premium to compensate for the inflation risk which was significantly increased during the year marked by a strong inflationary pressures (inflation reached $6.1 \%$ ), and moreover, a significant slowdown in the economic activity was recorded. Although the opposite sign, the values of risk premiums for inflation in 2004 and 2008 were equal, amounting to $0.03 \%$.

The remaining three macroeconomic factors, i.e. the industrial production, interest rates and oil prices, do not show statistical significance in the observed periods.

In Chen, Roll and Ross (1986), the results indicate that the most important factors affecting the expected stock returns on U.S. capital market are the industrial production, unanticipated changes in the risk premium, the unanticipated inflation, and, a somewhat weaker significance shows the unanticipated change in the term structure. Unanticipated inflation and changes in the the consumption and oil prices. In contrast, CROBEX proved to be the most important factor on the Croatian capital market. Differences in the results of the U.S. and the Croatian capital market analysis could be explained by the fact that the U.S. capital market is one of the most developed markets in the world which responds quickly to every publicly disclosed information. On the other hand, the Croatian capital market, as a relatively young market, possibly is not yet sufficiently developed to identify all information affecting the stock prices movement; therefore, only the official stock market index CROBEX, as a representative variable of the Croatian capital market, has shown to be a significant factor. Also, it should be noted that in the analysis of the U.S. capital market a much longer time period, namely twenty-seven years, was observed than on the Croatian capital market analysis. Therefore, longer time series is likely to lead to different results, so maybe a larger number of macroeconomic factors would prove to be significant.

\section{Conclusion}

This paper aims to investigate the relation between the stock return on Croatian capital market and macroeconomic factors. The analyses included fourteen stocks and five macroeconomic factors: inflation, industrial pro- 
duction, interest rate, market index and oil prices. By means of multiple regression of stock returns to macroeconomic factors' realizations, sensitivities of stocks to factors were estimated. The results showed that the market, i.e. the CROBEX index, has the largest statistical significance for all stocks and a positive relation to stock returns. Interest rates, oil prices and industrial production also mark positive relation to stock returns, while inflation influences negatively on a stock return. The next step included cross-sectional regression in which the estimated sensitivities were used as independent variables and stock returns in each month as dependent variables. This analysis resulted in time series of risk premiums for each macroeconomic factor. The most important factor affecting stock prices proved to be the CROBEX index, which had a positive risk premium. A statistically significant factor in 2004 and 2008 was also inflation, which marked a negative risk premium in 2004 and a positive risk premium in 2008. The remaining three macroeconomic factors, the industrial production, interest rates and oil prices, have not shown as significant.

Stock prices are greatly affected by investors' expectations so they respond very quickly to any publicly disclosed information, for example, economic or political news. For that reason, when analyzing influences on stock prices, whenever it is possible, it would be better to use indicators which measure changes in expectations about future values of macroeconomic factors, for instance, changes in expected inflation or economic activity, instead of indicators measuring the changes in realizations of macroeconomic variables. Particularly important indicators are those measuring unanticipated changes in future values of macroeconomic variables, regarding that investors could not prepare and protect themselves from such risks. Given that economic theory does not state which factors and the number of factors that should be used in the analysis, many possibilities of factor combinations are left open for future research.

\section{References:}

1. Bodurtha, J.N., Cho, D.C., Senbet, L.W. (1989). Economic Forces and the Stock Market: An international Perspective. The Global Finance Journal, 1(1), 21-46.

2. Campbell, J., Lo, A., MacKinlay, A. (1997). The Econometrics of Financial Markets, Princeton University Press, Princeton, New Jersey

3. Chan, K.C., Chen, N.F., Hsieh, D.A. (1985). An Exploratory Investigation of the Firm Size Effect. Journal of Financial Economics, 14, 451-471.

4. Chen, N., Roll, R., Ross, S.A. (1986). Economic Forces and the Stock Market. The Journal of Business, 59(3), 383-403.

5. Fama, E.F., French, K.R. (1992). The Cross-Section of Expected Stock Returns. The Journal of Finance,
47 (2), 427-465.

6. Hördahl, P. (2008). The Inflation Risk Premium in the Term Structure of Interest Rates. BIS Quarterly Review

7. Ivanović, Z. (2000). Faktorski modeli u funkciji procjene prihoda vrijednosnica. Ekonomski pregled, 51 (9-10), 987-1005.

8. McElroy, M.B., Burmeister, E. (1988). Arbitrage Pricing Theory as a Restricted Nonlinear Multivariate Regression Model: Iterated Nonlinear Seemingly Unrelated Regression Estimates. Journal of Business \& Economic Statistics, 6(1), 29-42.

9. Ross, S. (1976). The arbitrage theory of capital asset pricing. Journal of Economic Theory, 13 (3), $341-$ 360.

Dubravka Benaković is an expert associate in the Ministry of Finance of the Republic of Croatia. She graduated in 2005 from the Faculty of Economics and Business Zagreb and is currently finishing postgraduate study programme in International Economics and Finance at the same faculty. After graduating she started to work in Bureau for Macroeconomic Analysis and Planning of the Ministry of Finance. She attended several courses abroad on macroeconomics and finance.

Petra Posedel, PhD is a higher assistant at the Faculty of Economics and Business, University of Zagreb, Croatia. Her research interests are mainly focused on inference for stochastic processes, stochastic volatility models and applications of mathematical statistics and probability in finance. Petra Posedel has been involved in a few scientific projects since 2001 and has published several scientific and professional papers. She is a member of the organizing committee of the Croatian Quants Day Workshop in quantitative finan. 